\title{
Supramolecular Coordination Chemistry and Functional Microporous Molecular Materials
}

\author{
Peter H. Dinolfo and J oseph T. Hupp* \\ Department of Chemistry and Center for Nanofabrication and Molecular Self-Assembly, \\ Northwestern University, Evanston, Illinois 60208
}

Received March 2, 2001. Revised Manuscript Received May 8, 2001

\begin{abstract}
An enormous number and variety of discrete, isolable, supramolecular-coordinationchemistry-based assemblies featuring well-defined nanoscale cavities have been designed, synthesized, and characterized over the past decade. A small number of these have subsequently been used as building blocks for microporous materials and now comprise an important component of an emerging chemistry of microporous molecular materials. The extant materials typically have displayed large void volumes, high internal surface areas, and the ability to withstand the systematic removal of solvent. These and other properties (chemical tailorability, alignment of cavities to form extended channels, good processability, etc.) suggest a number of potentially very exciting applications invol ving sel ective mol ecular transport, sensing, or chemical transformation-with many of these now supported by proofof-concept experiments.
\end{abstract}

\section{Introduction}

Molecular chemistry is the chemistry of compounds formed via interactions between atoms. "Supramolecular chemistry" is the analogous chemi stry of assemblies formed via interactions between molecules. ${ }^{1}$ Molecular chemistry usually entails strong particle-particle interactions, such as covalent bond formation, and takes place on an angstrom scale. Supramol ecular chemistry involves weaker interactions-hydrogen bonding, dispersion interactions, electron-donor/el ectron-acceptor interactions, and so on-and usually takes place on a nanometer scale. Because the organizing forces in supramolecular chemistry generally are weak, advantage is often taken of: (a) favorable symmetry and entropy effects (for example, to achieve macrocycle formation at the expense of linear oligomer formation), (b) preprogramming of synthons toward a particular reaction direction (for example, cis vs trans coordination of a reactive metal center), (c) molecular or ionic charge, size, and shape complementarity (for example, to template the assembly of a desired higher-order structure), or (d) the reversibility of supramolecular association (for example, to obtain thermodynamic rather than kinetic products from assembly reactions). Sometimes two or more of these strategies can be combined to achieve "self-assembly"-meaning here the spontaneous formation of highly ordered, complex, symmetrical molecular or supramolecular structures in pure form, from many starting components (atoms, ions, ligands, etc.), in a single step.

One of the most rapidly devel oping areas of supramolecular synthetic chemistry is supramolecular coordination chemistry. A tremendous variety of metal-coordination-based grid structures, ladder structures, and other semi-infinite structures, ${ }^{2-9}$ as well as discrete molecular structures (triangles, squares, pentagons, hexagons, rectangles, cubes, cylinders, and more complex structures), ${ }^{10-13}$ have been obtained. ${ }^{14}$ Often, the semi-infinite structures are interpenetrating structures; there are significant thermodynamic structural and organizational incentives for materials interpenetration. Nevertheless, noninterpenetrating, open-channel structures-microporous structures ${ }^{15}$ - could be compelling from a functional perspective. Examples of noninterpenetrating, semi-infinite mi croporous structures have indeed been reported. ${ }^{7,16-23}$ Another approachthe focus of the article here-would be to construct and use molecular materials, i.e., materials composed of discrete molecular units, with the units held in place chiefly by van der Waals interactions. ${ }^{24}$ If the molecular units were cavity-containing cyclic molecules, the molecules defining the cavities conceivably could align and stack in the solid state to create semi-infinite channel structures.

Remarkably, for cyclic molecules based on multimetallic coordination chemistry, the most common configurations in the solid state-by far-are ones that achieve cavity alignment and channel formation. Shown in Figure 1 is a representative example: an X-ray determined structure of a single crystal of $\left[\mathrm{Pt}\left(4,4^{\prime}-\right.\right.$ bipyridyl)(dppp)(OTf) $]_{4}, \mathbf{1}$ (dppp = diphenyl phosphinopropane; OTf = trifluoromethanesulfonate). ${ }^{25}$ Omitted from the structure, for clarity, are eight counteranions per cationic metal locycle unit. The omitted ions occupy primarily the cavity/channel region of the structure, thereby largely precluding the idea of achieving nanoscale porosity. It would seem then that an additional requirement for microporous molecular materials formation is that the component molecular units be electrically neutral. ${ }^{26}$ As indicated below, a fair number of neutral, cavity-containing, cyclic coordination compounds-candidate microporous molecular materialsnow exist. 


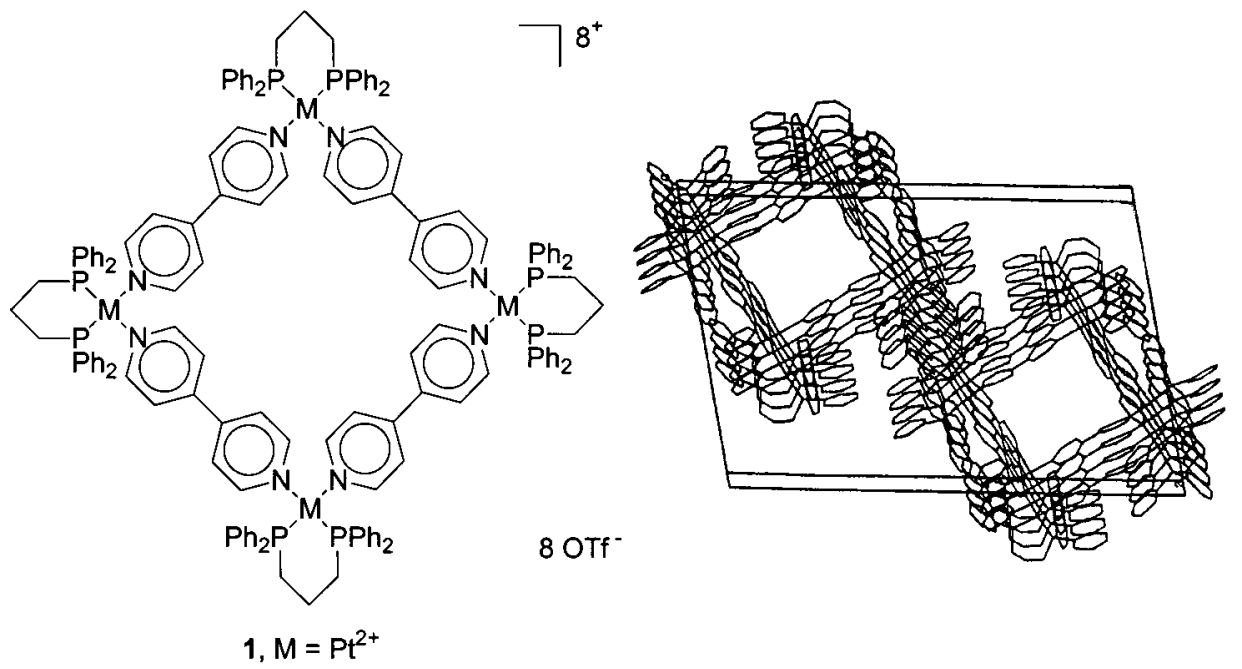

Figure 1. $\left[\mathrm{Pt}\left(4,4^{\prime}-\mathrm{bpy}\right)(\mathrm{dppp})(\mathrm{OTf})_{2}\right]_{4}(\mathrm{dppp}=$ diphenylphosphinopropane; OTf $=$ trifluoromethanesulfonate) square devised by Stang and co-workers with the crystal structure packing. The packing structure shows the presence of semi-infinite channels formed by the square openings. The eight triflate counterions per square occupy both the channels and interstitial spaces, precluding the use of these charged squares as microporous materials. Reprinted from ref 25.

The focus of this review is functional microporous molecular materials based on "supramolecular" coordination compounds. The functions we expl ore bel ow are molecular sieving or separations, selective chemical sensing, and selective chemical catalysis. Although no reports have appeared, one could certainly envision other functions such as light-harvesting and energy transfer for redox-based solar energy conversion (e.g., efficient sensitization of wide band gap semi conductors in photoelectrochemical assemblies), lasing by chromophoric arrays, and el ectroluminescence (light-emitting diode (LED) behavior). Because the notion of functional microporous molecular materials is still new, the number of studies described in the review is relatively few. At the same time, the fact that the area is still at an early formative stage of development suggests to us that tremendous opportunities exist for devising and developing interesting new science based on these and related materials.

\section{Available Materials}

Nominally required for functional microporous molecular materials formation are compounds featuring: (1) cyclic supramolecular structures (if we exclude clathrate compounds, dimeric hydrogen-bonded "molecular corner" compounds, ${ }^{27}$ and related compounds from consideration), (2) accessible cavities of useful size, (3) no catenation, (4) no counterions, ${ }^{26}$ and (5) sufficient stability to withstand removal of solvent molecules. The number of compounds satisfying these requirements is surprisingly few, although clearly the chemistry exists to construct many more. Of the available compounds, only a handful have been investigated from a functional microporous materials perspective. Comprising nearly all of this subset are molecular squares featuring cisligated $\mathrm{Re}(\mathrm{CO})_{3} \mathrm{X}(\mathrm{X}=\mathrm{Cl}$ or $\mathrm{Br})$ corners and rigid or semirigid difunctional azine or imine edges: compounds 2-9 shown. ${ }^{28-34}$ They are typically obtained in a single step, in nearly quantitative yield, via a "coordinative self-assembly" process (Scheme 1). ${ }^{31,35,36}$ The process makes use of $\operatorname{Re}(\mathrm{CO})_{5} \mathrm{X}$ as a simple synthon predisposed, via classical trans labilization effects, to liberate two

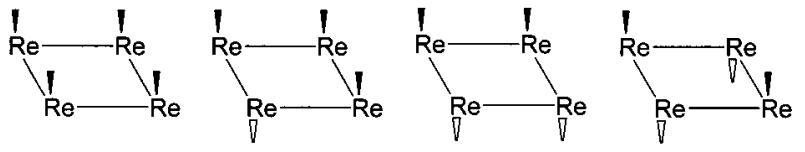

Figure 2. Schematic showing the four possible isomers of squares formed with $\mathrm{Re}(\mathrm{CO})_{3} \mathrm{Cl}$ corners. The dark arrow signifies the $\mathrm{Cl}$ pointing up, and the open arrow signifies the $\mathrm{Cl}$ pointing down.

(and only two) carbonyl ligands, exclusively from cis sites. Because the rhenium centers exist in oxidation state I (necessary for stable 18-electron organometallic complex formation), the anionic halide ligands are sufficient to reduce the overall charge to zero. It should be noted that because each of the four halide ligands can be oriented up or down with respect to a horizontal plane defined by the metal centers, the assembly process could yield as many as four structural isomers (all up, three up + one down, two up + two down (diagonal), two up + two down (adjacent); see Figure 2). M ost often observed in crystal structures is the "two up + two down (diagonal)" structure, presumably because packing is optimized, rendering this isomer easiest to crystallize. 29,35

Completing the subset are the 4,4'-bipyridine-bridged molecular rectangles, $\mathbf{1 0}$ and $\mathbf{1 1}$. These compounds have been obtained in $\mathrm{Mn}(\mathrm{I})$ and $\mathrm{Re}(\mathrm{I})$ form, via a two-step synthesis (Scheme 2). ${ }^{37}$ Providing charge compensation are doubly chelating, dianionic bis(benzimidazolate) ligands. Benkstein and Hupp found that chelating ligands were necessary for stable rectangle formation; their attempts to obtain rectangles instead by using mixtures of short and long nonchelating ligands such as pyrazine and 4,4'-bipyridine (either sequentially or simultaneously) invariably failed, with quantitative disproportionation into small and large molecular squares instead occurring. ${ }^{38-40}$

One of the more useful properties of $\mathbf{2 - 1 1}$ is their solubility in several common polar organic solvents. We find that the solubility can be exploited in thin-film fabrication. Reasonably uniform, pinhole-free films can be prepared in thicknesses ranging from ca. 40-1000 $\mathrm{nm}$ by slowly rotating (several $\mathrm{rpm}$ ) an inverted film 
Scheme 1
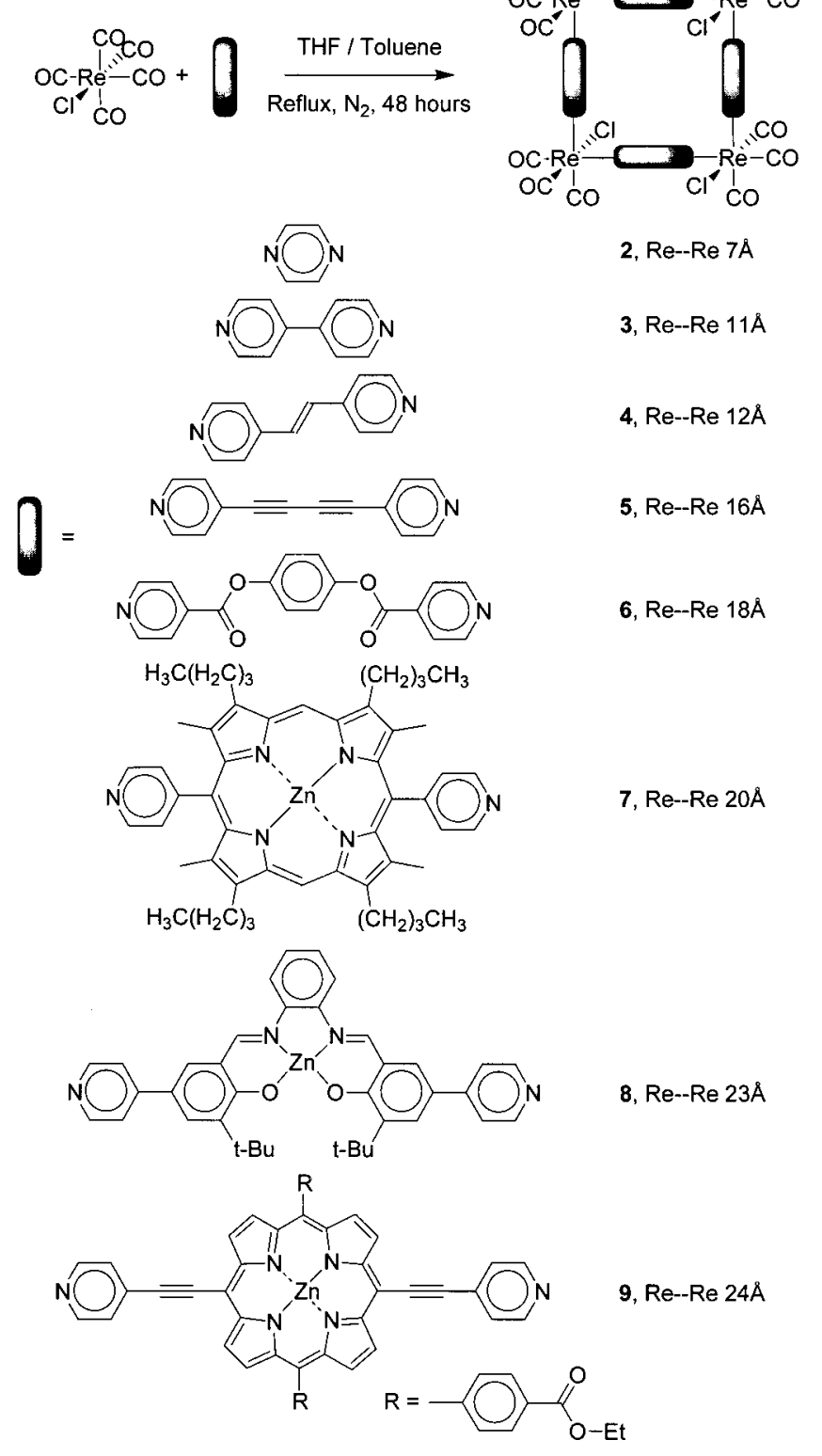

Scheme 2
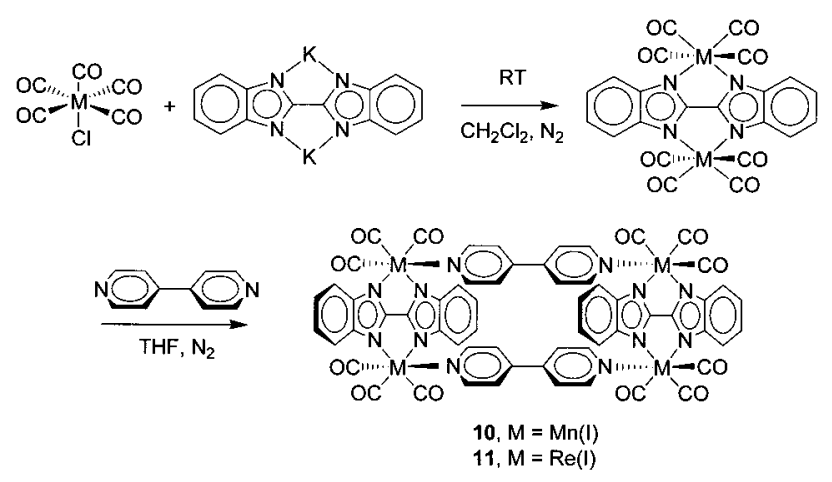

platform (for example a flat carbon or gold disk of a few square millimeters in area) to which a compoundcontaining droplet of volatile solvent adheres. ${ }^{41}$ The resulting films are characterized by complete insolubility in aqueous solutions-a highly desirable property for applications such as aquatic contaminant sensing. The
Scheme 3

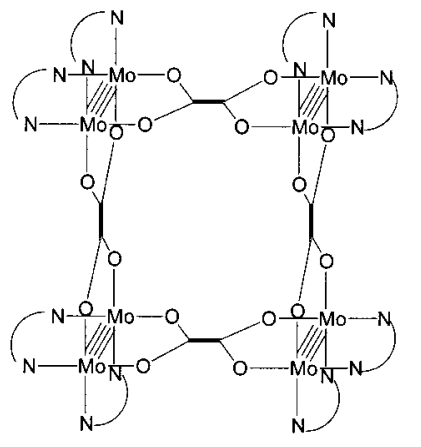

12

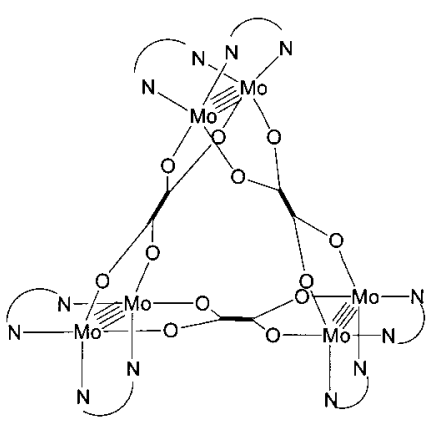

13

$$
\begin{aligned}
& \left.\gamma_{0}^{0}=\Theta_{0}^{0}\right\rangle\left\langle\gamma_{0}^{0}\right.
\end{aligned}
$$

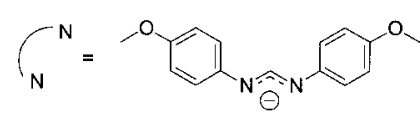

films also are insoluble in nonpolar solvents such as hexane. For most applications, films are first dried for several hours-either in air or in a vacuum. While NMR measurements of redissolved films typically show that a small amount of casting solvent is retained, the majority of solvent present in the initially cast film is removed. Furthermore, because the supramolecular coordination chemistry is reasonably robust, solvent removal does not precipitate the collapse of molecular cavities or the destruction of microporosity. This, of course, is an extremely useful property-and, indeed, an essential one for many applications. Available data for several of the compounds indicate void volumes approaching $50 \%$ and internal surface areas of as great as $42 \mathrm{~m}^{2} \mathrm{~g}^{-1}-$ numbers not unlike those for many zeolites. ${ }^{28}$

What about supramol ecular coordination compounds that have not been evaluated as functional molecular materials? Comprising one of the potentially most interesting collections are neutral compounds developed by Cotton and co-workers based on carboxylate coordination of $\mathrm{MO}_{2}{ }^{4+}$ and $\mathrm{Rh}_{2}{ }^{4+}$ corners to yield square or triangular assemblies-for example, compounds $\mathbf{1 2}$ and 13 (Scheme 3). In solution, these feature reversible and readily energetically accessible metal redox chemistry. ${ }^{42-44}$ Surprisingly, electrochemical reactivity has yet to be observed in the solid state (for example, thinfilm geometries) for any coordination-chemistry-based microporous molecular material. If the Cotton compounds (or other compounds) displayed reversible electrochemistry under these conditions, a number of interesting new functional applications would be opened up for exploration. Promising for the same reasons are resorcarene-based ${ }^{45,46}$ and ferrocene-based ${ }^{47-49}$ cyclic assemblies devised by Beer and co-workers. Other candidate compounds for microporous molecular materials studies include acetylene based squares, such as 14, developed by Youngs, Tessier, and co-workers; 50 hexametallic prisms $\mathbf{1 5}$ and $\mathbf{1 6}$, devised by Dinolfo, 51 and 17, devised by $L u ; 52$ triangular analogues of the tetrarhenium squares, $\mathbf{1 8}$ and $\mathbf{1 9}$, developed by Sun and Lees;31,32 square $\mathbf{2 0}$, made by J eong and Cho; 53 chiral Co(II )-tetraacetylethane squares, designed by Wang and Zhang; ${ }^{54}$ and 3-D prisms, designed by Cotton. ${ }^{55}$ 


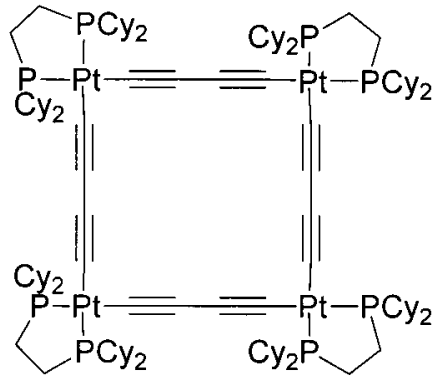

14

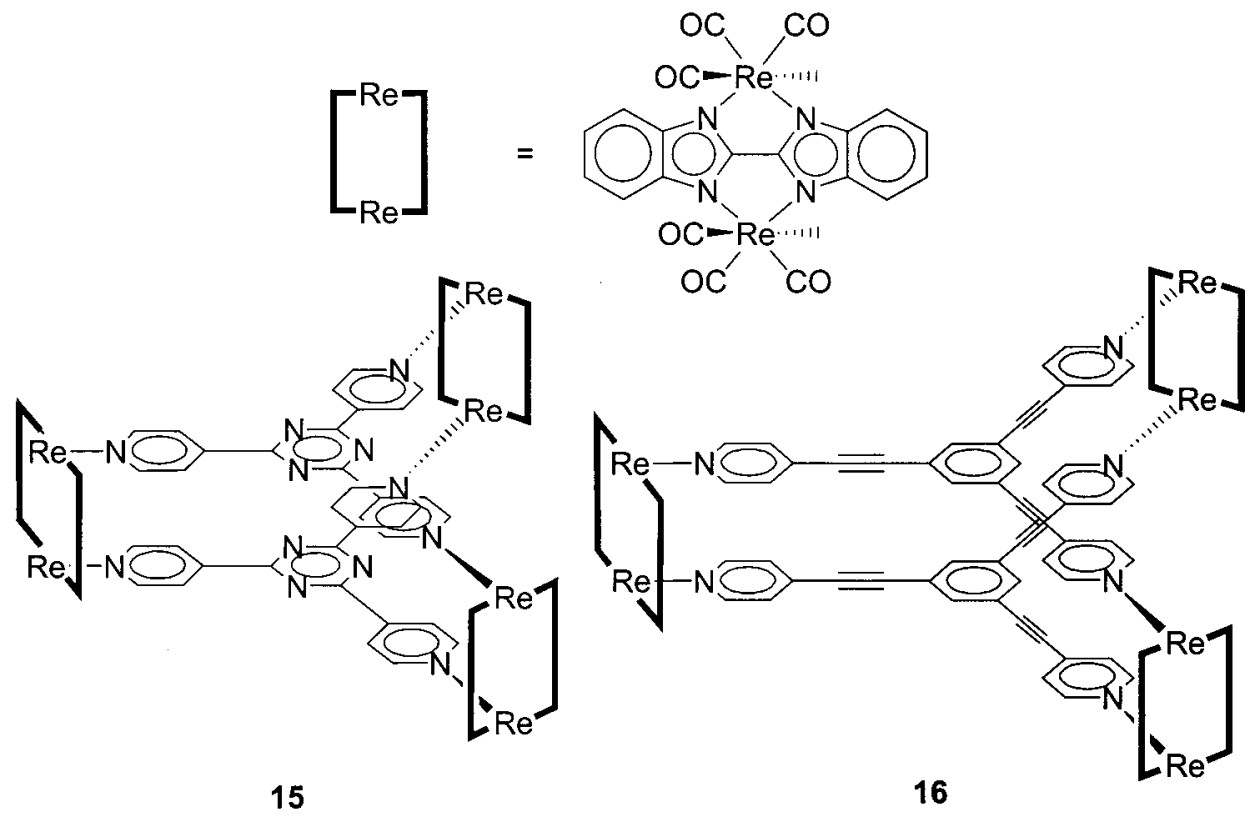

\section{Applications: Molecular Sieving}

A small number of reports have appeared on sizeselective mol ecular transport through thin-film molecular materials. Published studies are limited to squares or rectangles based on rhenium coordination chemistry. All studies to date have described condensed-phase

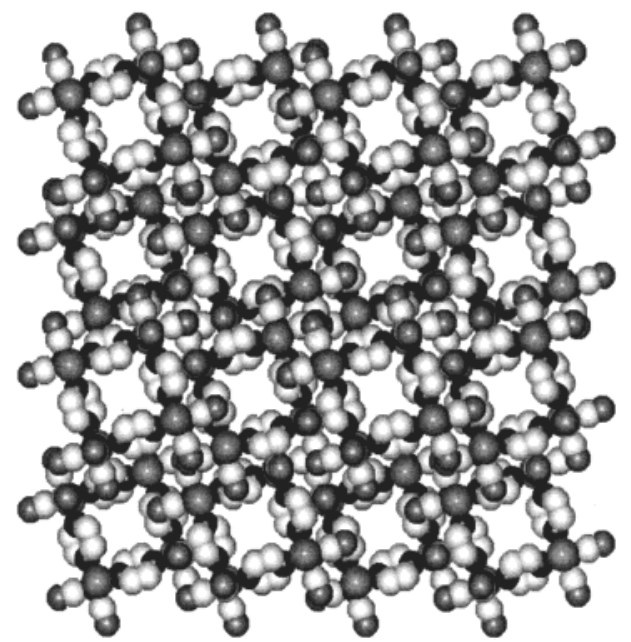

2 transport, generally with water as solvent. Clearly, however, vapor-phase transport studies could be of considerable interest. The initial studies in this area were carried out by Belanger and co-workers, who made use of el ectrochemical measurements to evaluate sizeselective transport or sieving: Thin films of molecular

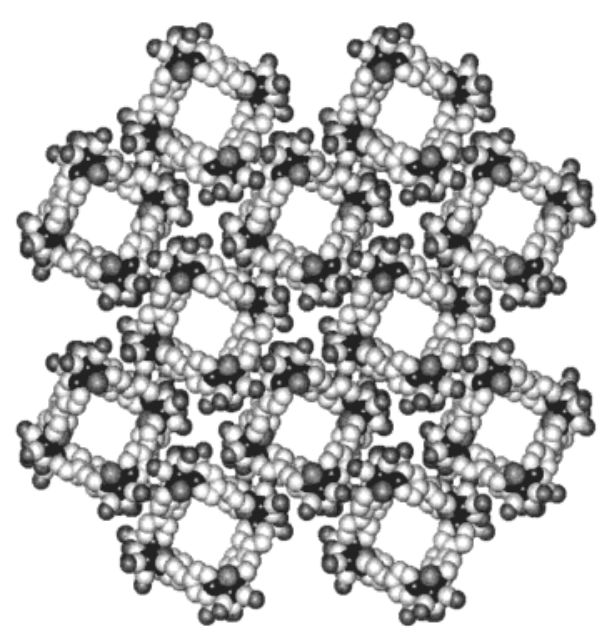

3

Figure 3. Space filled representation of the single-crystal X-ray structures of 2 and 3 viewed along the c crystallographic axis. The diagrams show the presence of aligned, open channels formed from the cavities in the mol ecular squares. Adapted from ref 28. 


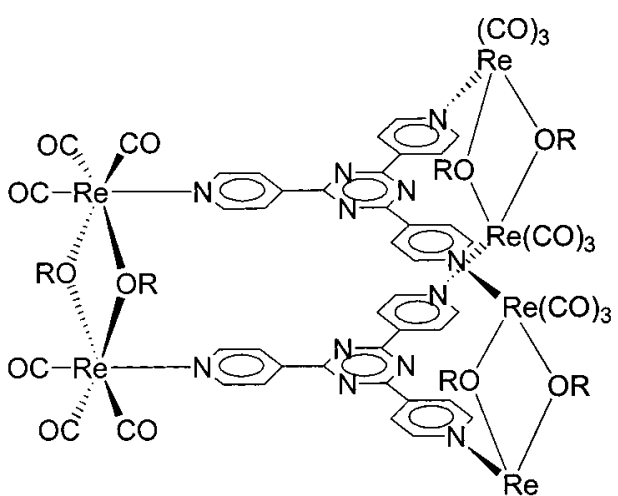

17, $\mathrm{R}=\mathrm{C}_{4} \mathrm{H}_{9}$
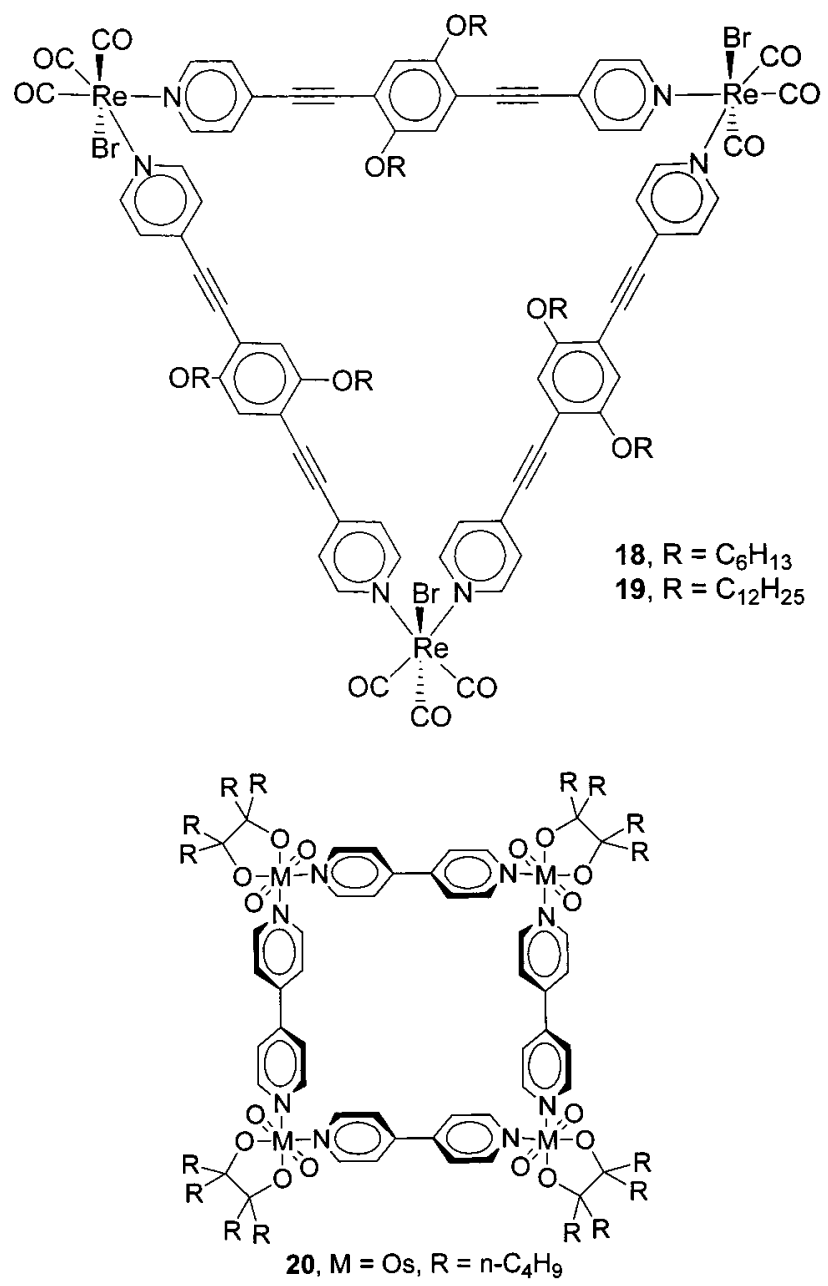

squares 2-4 and $\mathbf{7}$ were prepared on inert conductive platforms (gold, glassy carbon, indium-tin oxide, or platinum); the corresponding crystal structures of $\mathbf{2}$ and 3-space-filled representations of the molecular packing, viewed al ong the channels-are shown in Figure 3.35,41,56 The platforms were then used as working el ectrodes in el ectrochemical cells. By exposing the film-coated el ectrodes to solutions containing candidate redox-active permeants of various sizes, the authors were able to evaluate size cutoffs for transport by observing faradaic current flow, or its absence, in response to an appropriate voltammetric perturbation. Only those molecules capable of permeating the film and reaching the underlying electrode yielded voltammetric responses (Figure 4). In each case, the size cutoff for film transport

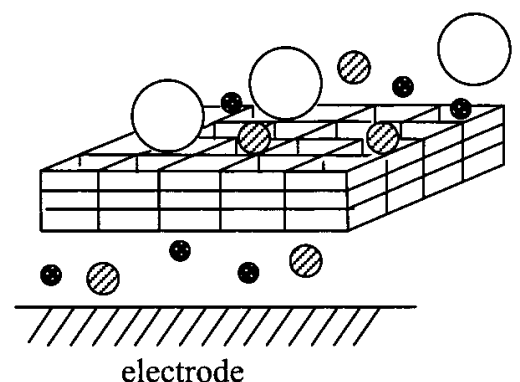

Figure 4. Schematic representation of film permeation studies using electrochemical techniques. The grids represent molecular squares in the form of a thin film on an electrode surface. Analytes that are small enough to permeate through the film reach the electrode, resulting in faradaic current flow. (Note that the diagram is not meant to imply that all squares, channels, and domains within a given film are aligned normal to the electrode surface.) Adapted from ref 56.

corresponded to the cavity size for an isol ated molecular square. Figure 5 shows a representative result: films based on the porphyrinic molecular square, 7, are blocking toward a $24 \AA$ diameter iron complex but permeable with respect to a $4.5 \AA$ diameter complex, consistent with a roughly $20 \AA$ mol ecular-square cavity size. Williams and Zhang showed that molecular sieving behavior persists even for thin films composed of the ca. $23-24 \AA$ cavity-diameter salen- and porphyrin-edged squares, 8 and $\mathbf{9 . 5 7}$

Belanger, and later Williams, showed that thin-film transport rates could be quantified by using rotating disk voltammetry and scanning electrochemical microscopy techniques, with the latter yielding higher precision measurements. ${ }^{41,58}$ They found that rates varied inversely with film thickness, consistent with a simple permeation model where diffusion of the permeant through the film, rather than partitioning from the solution into the film, is rate determining. From the transport rate measurements, together with film thickness measurements, they were able to determine "permeabilities": the products of solution-to-film partition coefficients and film-based molecular diffusion coefficients. For films composed of small to medium-sized squares ( $\mathbf{2}$ and $\mathbf{3}$ ), the measured permeabilities were found to be $20-50$ times greater than those observed for related amorphous metallopolymers featuring si milar size cutoffs. The enhanced transport for films based on molecular squares was tentatively ascribed to ordered channel formation, leading to comparatively straight rather than tortuous permeation routes. Consistent with this interpretation, low-resolution atomic force microscopy (AFM) suggests that films consist of submicron crystallites. ${ }^{28}$ Preliminary synchrotron-based $X$-ray studies of thin films of $\mathbf{2}$ indicated some degree of crystallinity. ${ }^{59}$ Thin films of the larger molecular square, 7, on the other hand, yield only moderately accelerated transport and seem to lack crystallinity on the basis of AFM and X-ray synchrotron measurements. ${ }^{59}$

In another study Belanger showed that transport versus blockage of redox inactive cations through thin films of the small pyrazine-bridged square, $\mathbf{2}$, could be evaluated by tracking the electrochemical response of a small redox-active counteranion, iodide; see Scheme 4 and Figure $6 .{ }^{60}$ Because of Coulombic interactions 


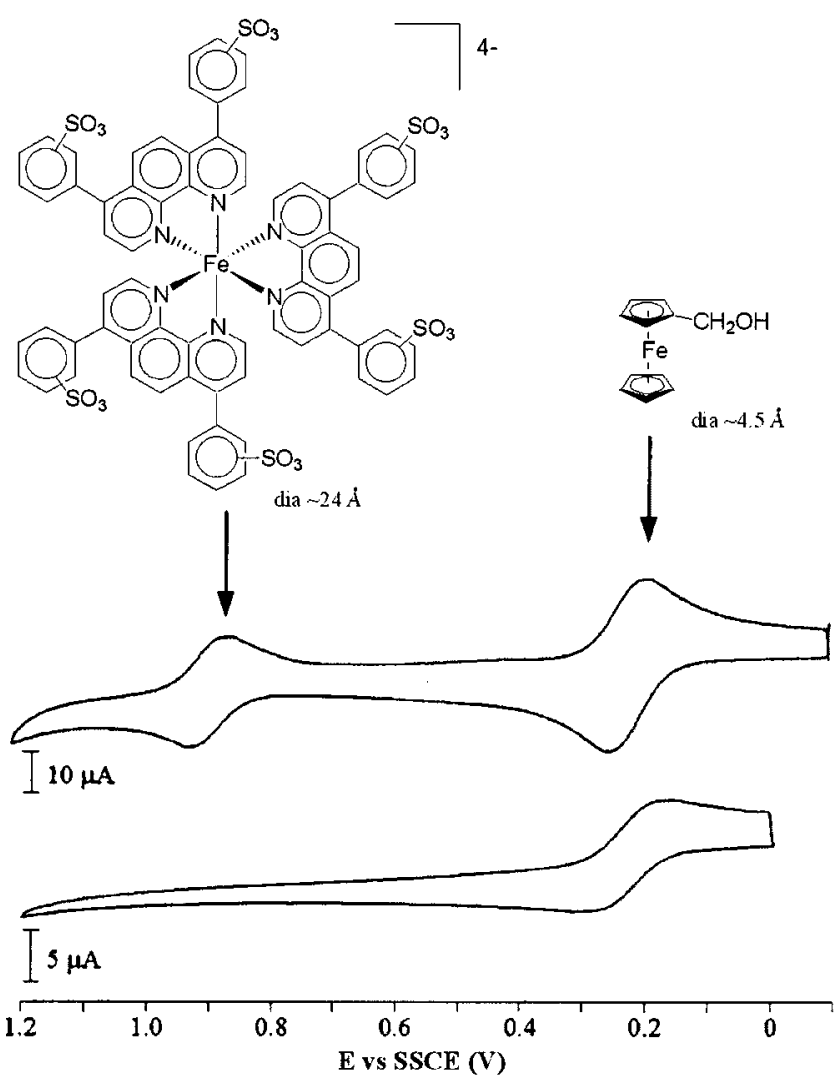

Figure 5. Cyclic voltammogram showing molecular sieving on a $190 \mathrm{~nm}$ thick film of $\mathbf{7}$ at the surface of a $3 \mathrm{~mm}$ diameter glassy carbon electrode versus the saturated standard calomel electrode. The permeate solution is an aqueous mixture of $\mathrm{FCCH}_{2} \mathrm{OH}\left(\mathrm{E}_{1 / 2} \approx 0.2 \mathrm{~V}\right.$, conc. $\left.=1.1 \mathrm{mM}, \mathrm{d} \approx 4.5 \AA\right)$ and $\left.\left[\mathrm{Fe}(\text { bphenSO })_{3}\right)_{3}\right]^{4-}\left(\mathrm{E}_{1 / 2} \approx 0.9 \mathrm{~V}\right.$, conc. $\left.=1.0 \mathrm{~m}, \mathrm{~d} \approx 24 \AA\right)$ (bphen $\mathrm{SO}_{3}=$ disulfonated bathophenanthroline). The top CV is from a bare electrode, and the bottom CV is from the filmcovered electrode. Adapted from ref 56.

\section{Scheme 4}

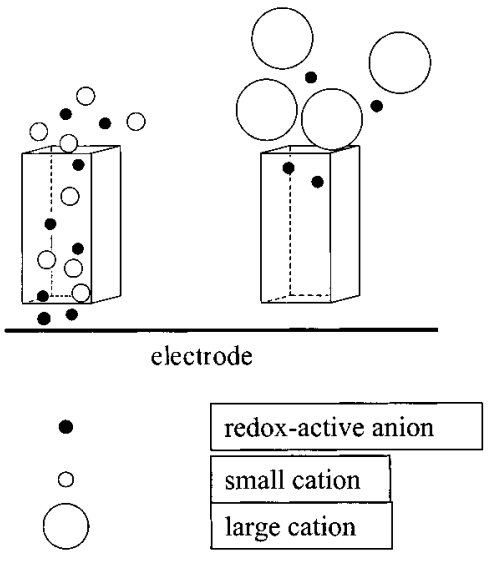

between the cation and "reporter" anion, the latter can appreciably permeate a film of several nanometer thickness only if the redox-inactive cation can also enter.

Belanger and Williams and their co-workers showed that size cutoffs for molecular sieving by thin films of porphyrinic molecular squares could be manipulated by chemically modifying the square cavities. ${ }^{56,58}$ In their studies, advantage was taken of zinc ions configured in the center of each porphyrin wall to axially ligate difunctional or tetrafunctional porphyrins and predictably reduce the cavity dimensions (F igure 7). Benkstein

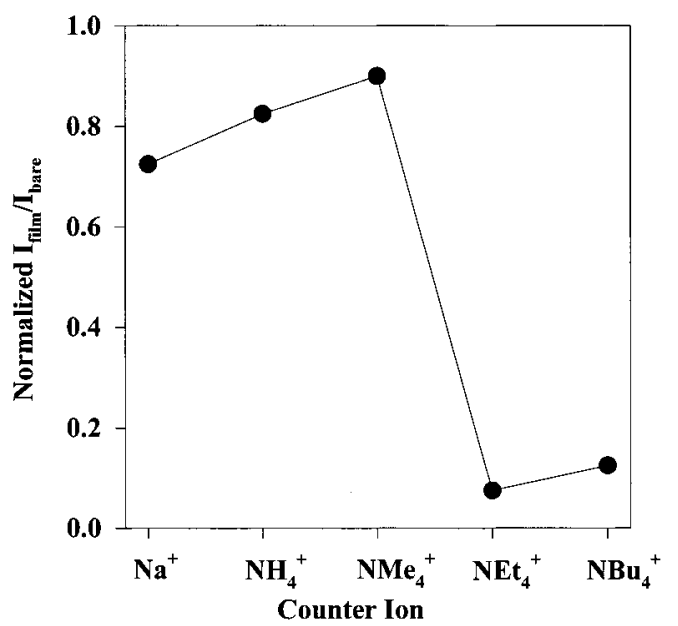

Figure 6. Plot of the normalized current ratio for the oxidation of $\mathrm{I}^{-}$vs the size of the counterion for a thin film of 2. The film is permeable to smaller counterions, while the

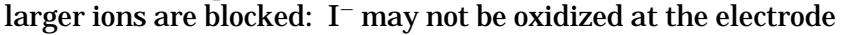
unless a charge-compensating cation permeates the film.

and Williams extended the investigations to thin films composed of the molecular rectangle, 10.61,62 Available crystallographic data show that $\mathbf{1 0}$ can pack in a way that yields one interstitial cavity for each intramolecular cavity (F igure 8$).{ }^{38}$ Both cavities are roughly rectangular, and the two kinds of cavities are similar in size. These investigators found that shape-selective molecular transport behavior could be observed. Appropriately sized el ongated molecules such as ethyl viologen, 21, and dinickel (1,1'-enebicyclo-3,6,10,13-tetraazatetradeca-2,13-dienylidene), 22, are readily transmitted, while spherical molecules of similar volume are excluded. Williams showed that transport through individual microcrystallites of molecular rectangles could be detected and quantified by using scanning electrochemical microscopy techniques. The transport rates obtained in this way were much smaller than those found for similarly sized squares, consistent with the absence of simple linear channels in the rectangle crystal structure.

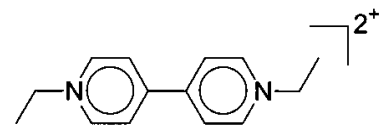

$$
\text { 21, dim: } \sim 3 \times 5 \times 14 \AA
$$

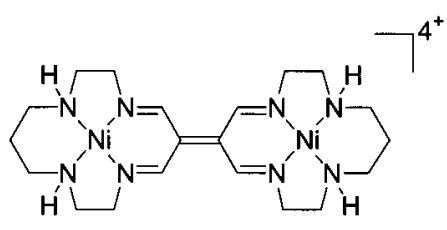

22, dim: $\sim 4 \times 8 \times 16 \AA$

Czaplewski and co-workers prepared thin films of squares $\mathbf{2}$ and $\mathbf{7}$ on porous polyester membrane supports. ${ }^{59}$ They found, depending on the preparative conditions, that they could obtain films that existed as layers on top of the membranes or that also infiltrated the roughly micron sized pores of the membrane. Molecular sieving was demonstrated by employing the supported films as separators between permeant- 

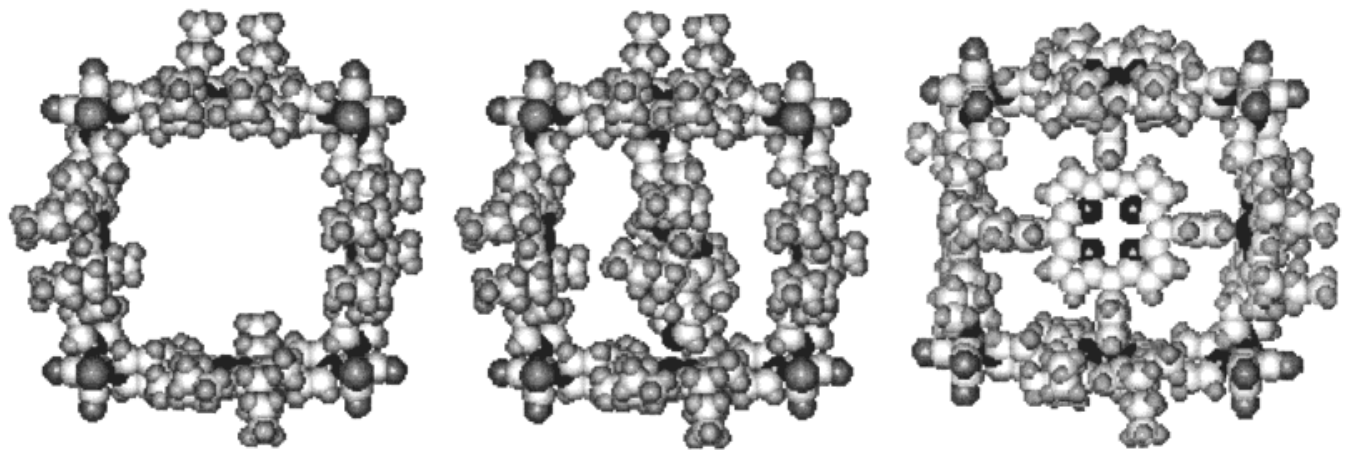

Figure 7. Space-filled models of por phyrin square 7 with (left) an empty cavity (dimensions ca. $18 \AA \times 18 \AA$ ), (middle) a dipyridyl porphyrin bound between two adjacent walls (ca. $18 \AA \times 8 \AA$ ), and (right) a tetra-pyridyl porphyrin bound to all four walls (ca. $4.5 \AA \times 4.5 \AA)$.

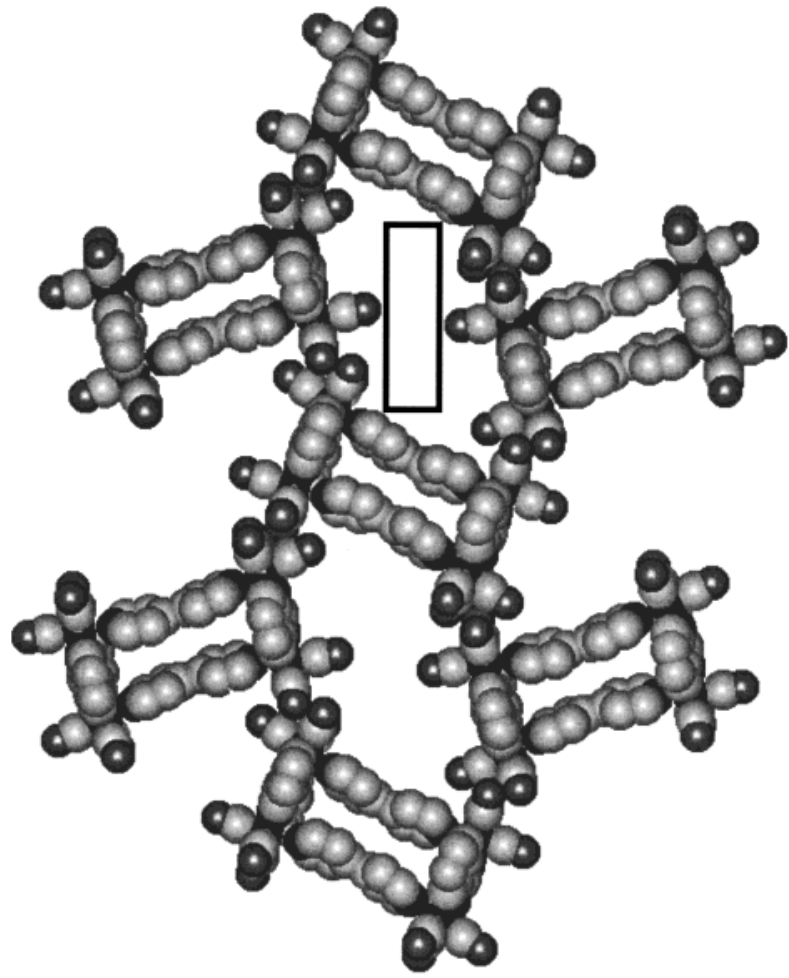

Figure 8. Crystal structure packing diagram for the $\mathrm{Mn}$ rectangle $\mathbf{1 0}$ (the protons and solvent molecules are omitted for clarity), showing one intermolecular (drawn box) and one intramolecular cavity for each molecule. Adapted from ref 38.

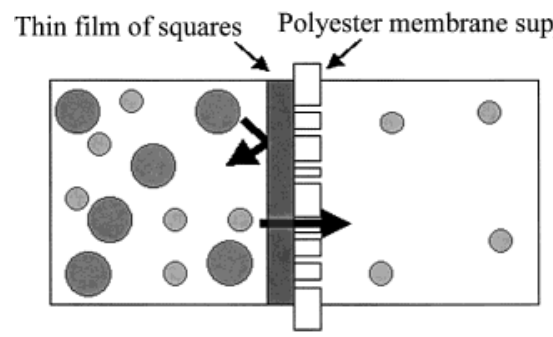

Figure 9. Schematic representation of a size-selective permeation experiment. Thin films of molecular squares $\mathbf{2}$ and $\mathbf{7}$ were cast on supporting polyester membranes. The solution on the left initially contains a known amount of analytes, while the solution on the right is initially free of analytes. The film allows selective transport of analytes based on size. Adapted from ref 59 .

molecule-containing reservoirs and initially permeantfree receiving solutions (Figure 9). Transport of the chromophoric permeant molecules was detected by electronic absorption measurements of the reservoir solution. Quantitative transport studies yiel ded permeabilities that agreed reasonably well with those obtained from electrochemical studies of much thinner films (ca. $10 \mu \mathrm{m}$ vs tens to hundreds of nanometers). Following Belanger, the authors also showed that the size cutoff in the sieving experiments could be tuned by derivatizing the interiors of porphyrin-based squares; see Figure 7. In follow up work, they found that chemical selectivity could be induced: Porphyrin squares were modified by axially tethering imine-derivatized poly(ethylene glycol) strands to the available zinc sites. Thin films consisting of these modified squares showed a very substantially enhanced ability to transport hydrophilic permeants at the expense of hydrophobic permeants.

\section{Applications: Chemical Sensing}

While a number of reports exist on the behavior of cavity-containing supramolecular coordination compl exes as hosts for atomic or molecular guests, ${ }^{63-79}$ only a small number have additionally described bindingsignal transduction behavior such that the assemblies can function as chemical sensors. ${ }^{30,80-87}$ Even fewer have focused on such behavior in the solid state. $28,31,35,38$ A potentially significant advantage of a solid-state or materials approach over, for example, an approach based on a monolayer of receptor molecules, is the higher guest-uptake capacity available. Depending on the mode of signal transduction for successful uptake events, the higher capacity can translate into proportionately lower guest detection limits. Thin films used in recently published studies typically have contained the equivalent of a few hundred to several hundred monolayers of host compound, suggesting a sensitivity advantage of roughly $2-3$ orders of magnitude. In principle, thicker films could be employed; at some point, however, guest transport kinetics can be expected to degrade sensor response or recovery times unacceptably. ${ }^{88}$

One report, by Sun and Lees, took advantage of the charge-transfer based photoluminescence of thin films of $\mathbf{5}$ to detect volatile nitroaromatics-surrogates for explosives such as trinitrotoluene. ${ }^{31}$ These authors found that van der Waals binding of the nitroaromatics extinguished the films' photoluminescence, almost certainly via a redox quenching mechanism with the guest molecule functioning as an electron acceptor and the photoexcited host functioning as an electron donor. 
Notably, thin-films of the corresponding "corner" complex, 23, proved unresponsive, ${ }^{31}$ consistent with available structural evidence for the absence of microporosity for this class of compounds. ${ }^{89}$ In principle, given the predominantly triplet nature of the charge-transfer excited states and the correspondingly long excited-state lifetimes, one guest molecule could quench the luminescence of any one of several dozen or more surrounding chromophoric molecular squares, since the initial excitation should be followed by square-to-square energy transfer. If the exciton hopping time is short in comparison to the excited-state emission lifetime, many hops can occur as the exciton migrates randomly toward a possible quenching encounter with an incorporated guest molecule. As shown by Swager and co-workers for a somewhat different family of chemosensory materials, ${ }^{90-94}$ the suggested effect represents an amplification of the sensing process and should result in lower guest detection limits than achievable in the absence of exciton hopping. It would be interesting to ascertain whether such a model holds for the system studied by Lees.

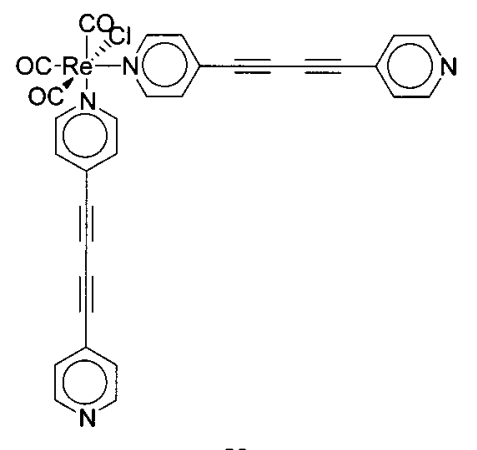

23

Keefe and co-workers examined the viability of thin films of 3, as well as films of the small molecular square 2, as chemosensory materials. ${ }^{28}$ These authors relied upon quartz crystal microgravimetry (QCM) ${ }^{95,96}$ for signal transduction and, like Sun and Lees, focused their studies on guest uptake from the vapor phase. They observed that these high-porosity materials: (a) responded reversibly with respect to guest uptake, typically on a time scale of several seconds, (b) proved capable of discriminating candi date guest molecules on the basis of size, (c) displayed a preference for aromatic guests over aliphatic guests, and (d) showed higher affinities for arene guests featuring el ectron donating groups than for arenes featuring electron-withdrawing groups; see Figure 10. The last observation was tentatively interpreted in terms of electron donor/acceptor contributions to guest:host binding. The authors additionally observed that thin films of related "corner" complexes did not exhibit guest binding behavior.

Benkstein extended the thin-film QCM studies to the molecular rectangle, 10.38 $\mathrm{He}$ found that the rectanglebased materials displayed 5- to 10-fol d higher affinities for arene guests than did materials based on similarly sized molecular squares. Figure 11 shows a representative binding curve derived from QCM data. Higher affinities, of course, translate into lower detection limits in guest sensing experiments. Benkstein also found that the rectangles were superior to the squares in discriminating between simple arene guests on the basis of

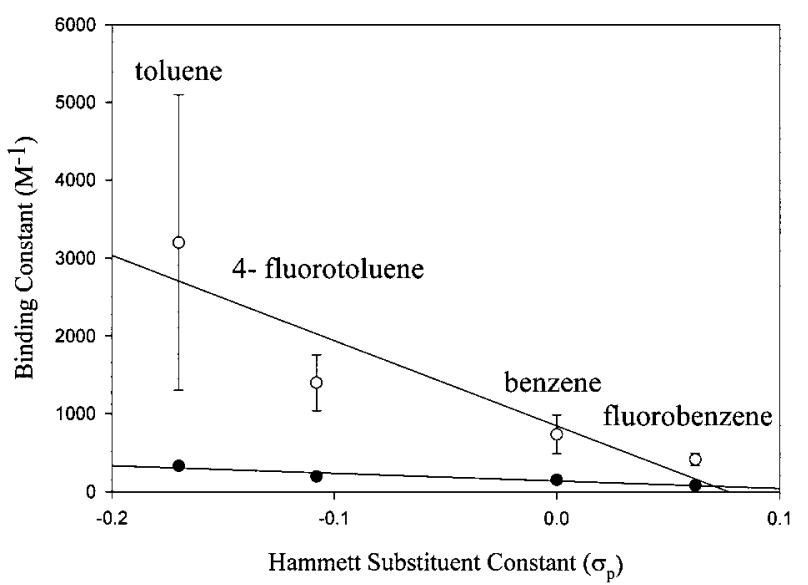

Figure 10. Correlation between thin-film host/guest binding constants, derived from QCM studies, and Hammett substituent constants $\left(\sigma_{\mathrm{p}}\right)$ for volatile arene guests. ${ }^{115}$ The host materials are compounds $\mathbf{2}$ (solid dots) and $\mathbf{1 0}$ (open dots). The guests are toluene, 4-fluorotoluene, benzene, and fluorobenzene. The $\sigma_{\mathrm{p}}$ value for 4-fluorotoluene used was the sum of the substituent constants for toluene and fluorobenzene.

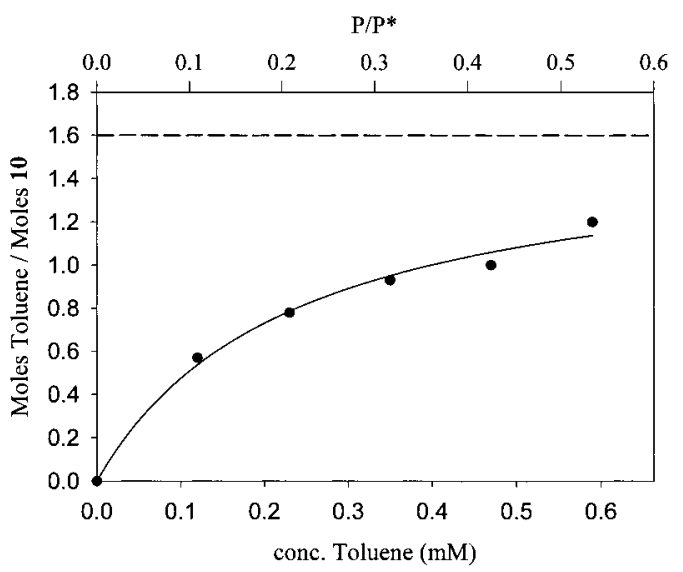

Figure 11. QCM-derived affinity data and best fit (solid line) for toluene uptake by a thin film of $\mathbf{1 0}$. The films were placed in a vacuum for a minimum of $8 \mathrm{~h}$ prior to the measurement to remove encapsulated solvent molecules. The y axis shows the molar ratio of adsorbed guest toluene to host $\mathbf{1 0}$ in the film. From the fit line, the limiting host-to-guest ratio is $\sim 1.6$ (dashed line). F or reference, the top axis provides the absolute pressure of toluene ( $\mathrm{P}=$ pressure of toluene in the QCM chamber; $\mathrm{P}^{*}=$ saturation vapor pressure of toluene at $24^{\circ} \mathrm{C}$ ). Adapted from ref 38 .

substituent composition; see Figure 10. Both effects were attributed to improved host:guest shape complementarity. Benkstein additionally reported limiting guest:host stoichiometries that significantly exceeded 1:1 and approached 2:1 (see Figure 11). The high stoichiometries were taken as possible evidence for binding within both intramolecular and interstitial cavities (see Figure 8, above).

Benkstein also reported on the photo luminescence behavior of thin films of $\mathbf{1 1}$ upon exposure to candidate guest species. ${ }^{38} \mathrm{He}$ examined several volatile organic guest molecules and found that some guests increased the emission quantum yield, while others decreased the yield. The effects, while small, were somewhat surprising since none of the guests were capable of either redox quenching or energy-transfer type quenching. It was suggested that the effects might represent guest- 


\section{Scheme 5}
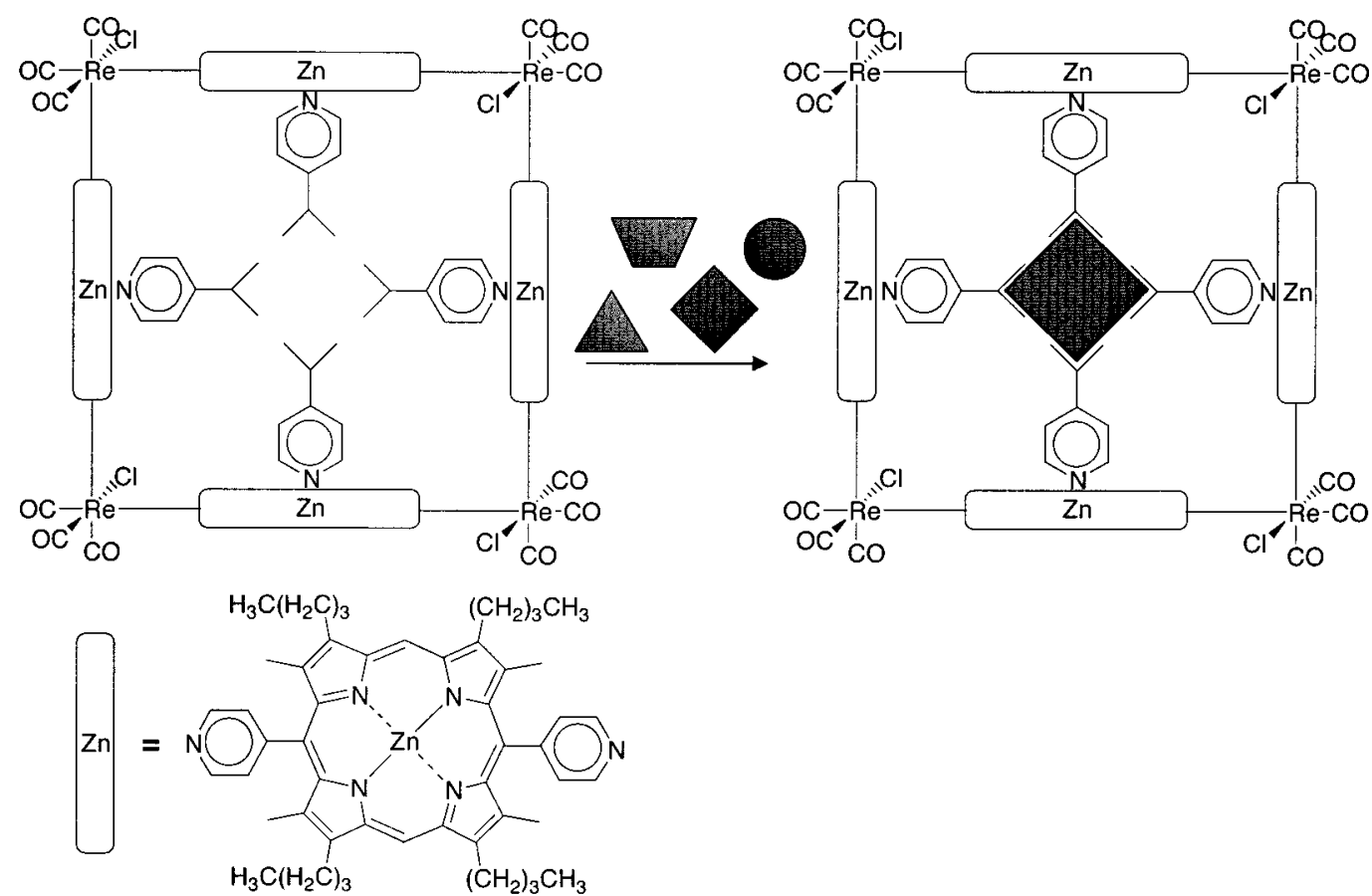

N $>$ Tunable unit which alters binding pocket properties

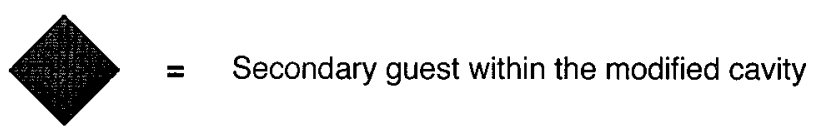

induced energy-gap-law effects, where rates of nonradiative decay decrease (and emission yields increase) as the excited-state/ground-state gap increases.

In an effort to tailor cavities and channels in ways that lead to increased selectivity of guest molecule or atom binding, Belanger and co-workers showed that molecular cavities within thin films of the porphyrinic square, 7, could be systematically modified via axial ligation of imine derivatives to available zinc sites. ${ }^{97}$ The concept is illustrated in Scheme 5. The authors were able to demonstrate cavity modification, within intact films, with 40 distinct ligands; they emphasized that the separate preparation of this many new cavitycontaining assemblies, as opposed to systematically functionalizing a single existing template, would be an enormously more labor-intensive undertaking. Chang and Slone showed-in a solution environment-that functionalizing assembly 7's cavity with crown-ethercontaining imine ligands could engender chemoresponsiveness to alkali metal ions, where signal transduction was accomplished via porphyrin fluorescence. ${ }^{98}$ Tzeng has shown-in thin film environments-that cavities can be functional ized with receptors for zinc ions (tethered carboxylates) and for iodine vapor (charge-transfer complex formation with tethered thiols). ${ }^{99}$ Although not explicitly directed at chemical sensing, Stang and Whiteford, ${ }^{63-65}$ as well as Youngs and ALQaisi, have shown that molecular squares featuring ethynyl groups can bind silver ions via a "pi-tweezer" effect.100,101 As illustrated in Figure 12, 24 can bind two silver ions, which can subsequently be used to bind difunctional molecules such as phenazine.

\section{Applications: Chemical Catalysis}

In principle-and by analogy to catalytic zeolites-the channel and cavity structures of microporous molecular materials, with their constrained spaces and fixed binding sites, could serve as versatile and effective catalysts, or components of catalysts, for a large number of chemical reactions. Molecular materials, however, are much less robust than inorganic zeol ites. Consequently, to be of real value, it is likely that high-value-added processes invol ving delicate reactants or products would need to be targeted. To the best of our knowledge, however, no reports of chemical catalysis by these materials have yet appeared. Nevertheless, an indication of what might initially be accomplished here is suggested by three recent reports. Fujita and Ito were able to accomplish the Wacker oxidation of styrene in the aqueous phase through reverse phase-transfer catalysis using a hexametal lic supramolecular complex based on Pt(II )ethylenediamine corners and tri-pyridyltriazine sides. ${ }^{102}$ Merlau and co-workers showed that several benefits accrued from encapsulation of manganese-porphyrin-based epoxidation catalysts within the tetraporphyrinic square assembly, 7.103 Catalysts of this kind have attracted considerable attention as models for the active site of cytochrome P450.104-106 Briefly, Merlau observed that encapsulation (1) extended cataIyst lifetimes by up to 2 orders of magnitude by reducing the frequency of destructive bimolecular catalystcatalyst encounters, (2) induced significant substrate size-selectivity by sterically excluding oversized substrates from the reaction cavity, and (3) permitted 


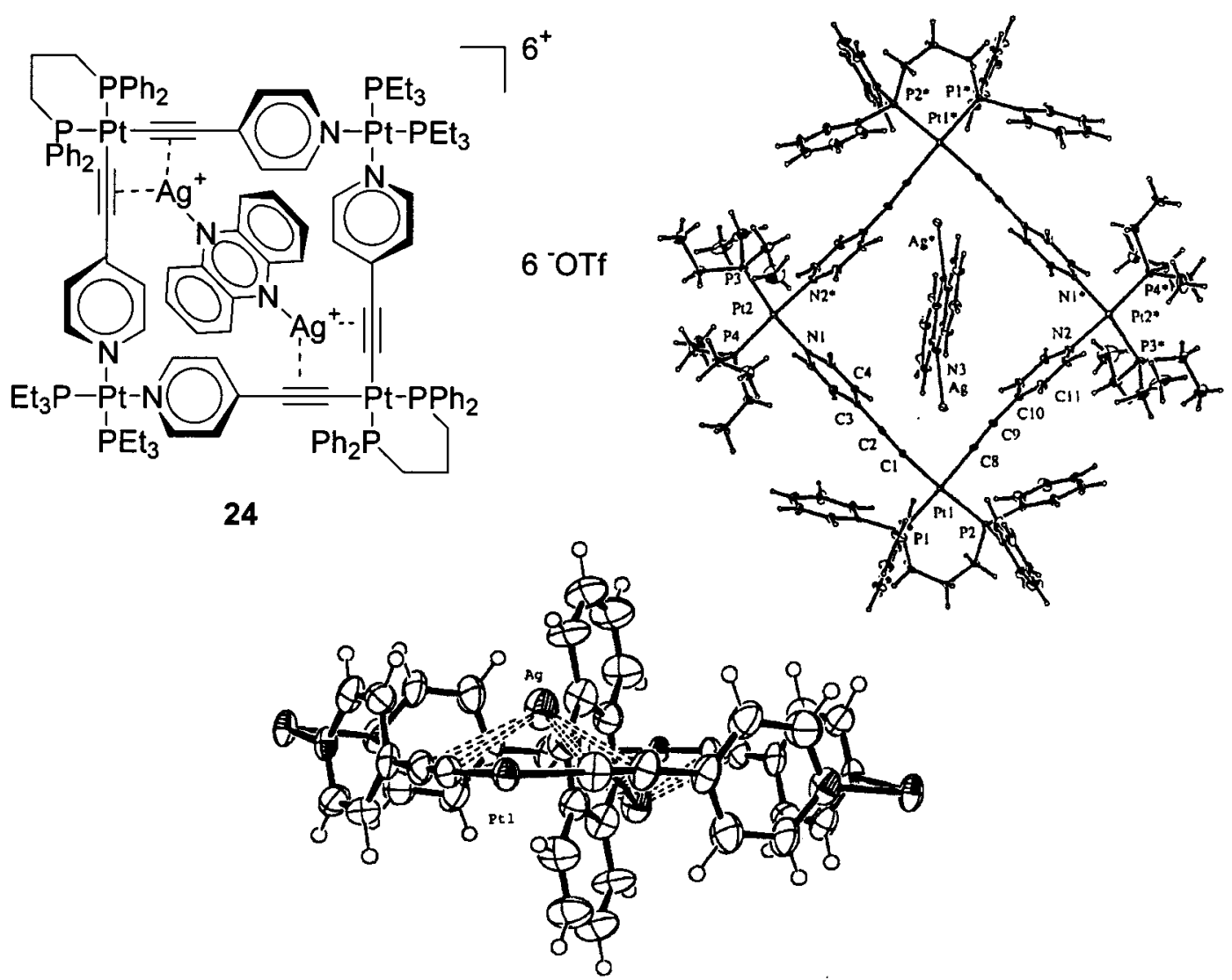

Figure 12. Top and side ORTEP views of complex $\mathbf{2 4}$ showing the phenazine bound ligand between two $\mathrm{Ag}^{+}$atoms. The $\mathrm{Ag}^{+}$ atoms are connected to the al kyne spacers of the square corners through a " $\pi$-tweezer effect." Six triflate counterions are omitted for clarity. ORTEP views reprinted from ref 63.

\section{Scheme 6}

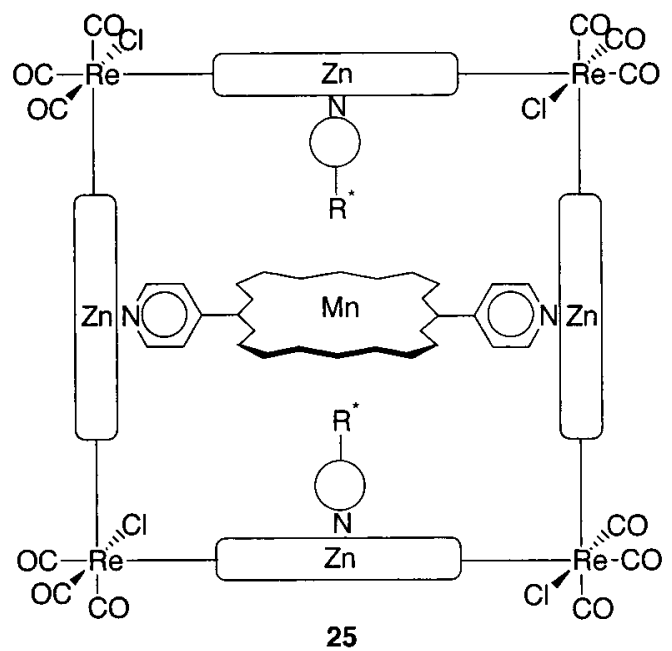

modulation of the cavity size and, therefore, the substrate size selectivity, via further chemical functionalization of the cavity; see, for example, assembly $\mathbf{2 5}$ (Scheme 6). These authors additionally attempted to engender enantioselectivity by employing chiral ligands as cavity modifiers; again, see Scheme 6 . That enantioselectivity was not observed in these preliminary studies was ascribed to the inherent torsional flexibility of the encapsulated catalyst and the opposing walls of the square and to the excessive distance between the optically active carbons of the modifier and the catalytic manganese ion. Finally, Morris and Nguyen observed similar enhancements in epoxidation catalyst lifetime

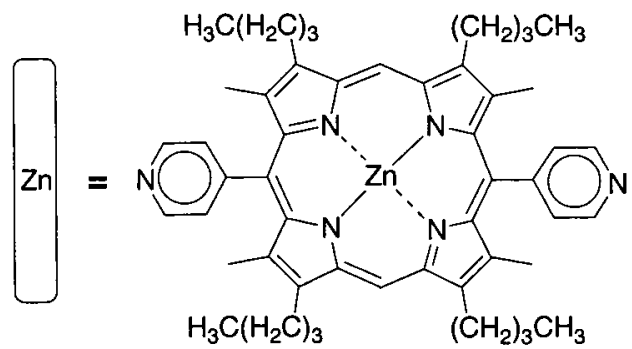

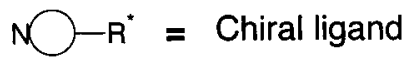

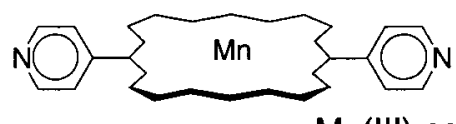

$=\mathrm{Mn}(\mathrm{III})$ porphyrin catalyst

with the metal-salen-based assembly, 26. ${ }^{34}$ The catalyst here is inherently enantioselective and is essentially a "supramolecular complex compatible" version of J acobsen's catalyst. ${ }^{107-109} \mathrm{~N}$ otably, the authors found that encapsulation did not significantly degrade the enantioselectivity of the catalyst.

\section{Conclusions and Prospectus}

An enormous number and variety of discrete, isolable, supramolecular-coordination-chemistry-based assemblies featuring well-defined nanoscale cavities have been designed, synthesized, and characterized over the past 


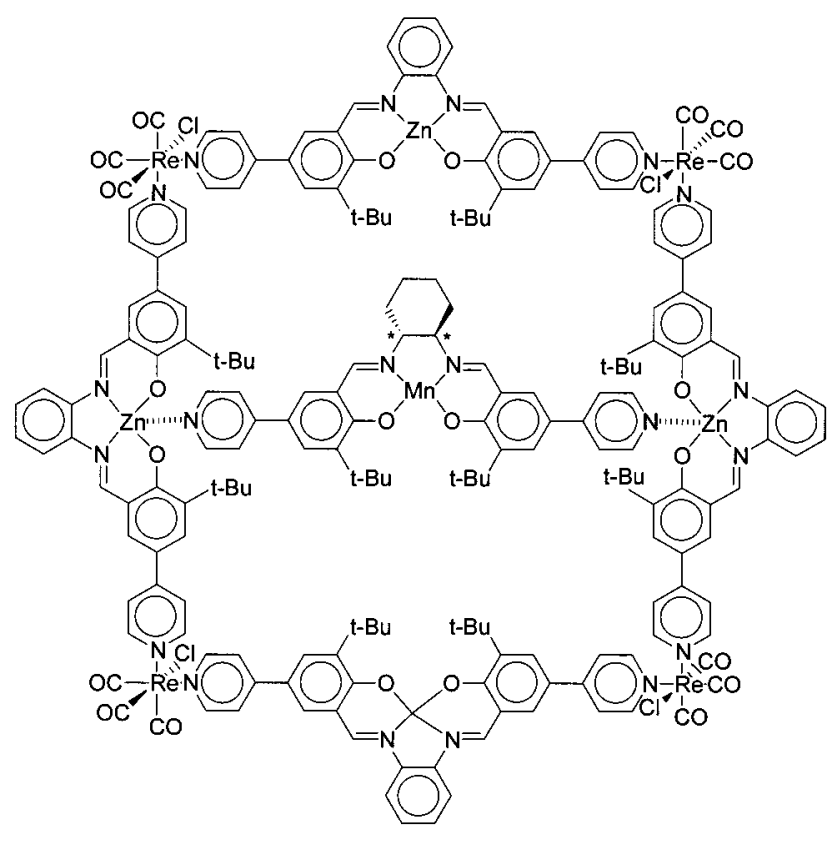

26

decade. A small number of these have subsequently been used as building blocks for mi croporous materials and now comprise an important component of an emerging chemistry of microporous molecular materials. The extant materials typi cally have displayed large void volumes, high internal surface areas, and the ability to withstand the systematic removal of solvent. These and other properties (chemical tailorability, alignment of cavities to form extended channels, good processability, etc.) suggest a number of potentially very exciting applications involving selective molecular transport, sensing, or chemical transformation-with some of these now supported by proof-of-concept experiments.

Electrode-supported and porous-membrane-supported thin films have been used to demonstrate shape-, size-, and chemical-composition-selective transport of candidate permeant molecules. In some cases, substantially accelerated molecular transport has been demonstratedeither based on favorable alignment of cavities to form useable channels or based on favorable partitioning of desired molecules into films. The possibility of altering transport selectivity by functionalizing cavities has been demonstrated. The prospects for further development likely center on: (a) further tailoring to achieve better or more sophisticated transport selectivity, (b) the introduction of external ly addressable gates or switches within the materials, and (c) the incorporation of tethered or mobile channel moieties capable of "facilitated transport."110-114 In addition, to enhance molecular fluxes, it will be important to learn how to construct even thinner films or membranes, ideally featuring selfannealing properties and enhanced mechanical stability. This likely will entail a departure from a purely "molecular materials" design motif and the development of new materials derived from polymerizable analogues of existing or new cavity-containing compounds.

The microporosity of available coordination-chemistrybased molecular materials has also been exploited for chemical sensing, both in vapor-phase and condensedphase environments. Because the building blocks for the chemosensory materials are molecular, well-defined cavities-candidate host sites for selective host:guest complex formation-generally exist. Size-selective and moderately chemical-composition-sel ective sensing of volatile organic guest compounds has been demonstrated with thin films of molecular squares, with signal transduction via photo luminescence or quartz crystal microgravimietry. Enhanced sensitivity and sel ectivity have been achieved with related materials that more adequately match host cavity shapes to guest shapes. Chemically selective sensing has been demonstrated on the basis of postsynthetic tail loring of large host cavities with appropriately specific receptor or binding groups. The susceptibility of selected cavities to controlled chemical modification suggests that the marriage of receptor chemistry with microporous molecular materials chemistry could prove very productive in the context of further chemosensory materials development. In addition to more sophisticated cavity functional ization, however, the development of useful new microporousmolecular-materials-based sensors could cl early benefit from the development or implementation of alternative modes of signal transduction.

Finally, on the basis of the available solution-phase studies, the prospects for useful and/or chemically interesting catalysis with coordination-chemistry-based microporous molecular materials also are good. One possible operational scheme would be a membrane catalytic reactor configuration that combines chemical separations with catalytic chemical transformation. Another would be microporous thin-film el ectrocatalysis. It seems likely, however, that in order to have significant impact, any effort in catalysis will need to target high-value-added reactions-for example, reactions occurring with high enantiosel ectivity. Depending on how robust the catalytic molecular materials can ultimately be made, it may also be necessary to target reactions involving delicate reactants or products that require handling or processing under comparatively mild conditions.

Acknowledgment. We gratefully acknowledge the efforts of our colleagues at Northwestern whose work we have cited. We thank the National Science F oundation for financial support of our work.

\section{References}

(1) Lehn, J . M. Supramol. Chem. 1995.

(2) Yaghi, O. M.; Li, H.; Davis, C.; Richardson, D.; Groy, T. L. Acc. Chem. Res. 1998, 31, 474-484.

(3) Li, H.; Eddaoudi, M.; O'Keeffe, M.; Yaghi, M. Nature 1999, 402 276-279.

(4) Swiegers, G. F.; Malefetse, T. J . Chem. Rev. 2000, 100, 34833537.

(5) Zaworotko, M. J . Nature 1999, 402, 242-243.

(6) Zaworotko, M. J . Angew. Chem., Int. Ed. Engl. 2000, 39, 30523054.

(7) Batten, S. R.; Robson, R. Angew. Chem., Int. Ed. Engl. 1998, 37, 1461-1494, and references therein

(8) Hagrman, P. J .; Hagrman, D.; Zubieta, J . Angew. Chem., Int. Ed. Engl. 1999, 38, 2639-2684.

(9) We also draw attention to the special issue in J. Solid State Chem. with co-editors O. M. Yaghi and M. O'Keeffe: J. Solid State Chem. 2000, 152, 1-2

(10) Leininger, S.; Olenyuk, B.; Stang, P. J . Chem. Rev. 2000, 100, 853-907.

(11) Fujita, M. Chem. Soc. Rev. 1998, 27, 417-425.

(12) Holliday, B. J .; Mirkin, C. A. Angew. Chem., Int. Ed. Engl. 2001, 40, 2022-2043.

(13) Stang, P. J .; Olenyuk, B. Acc. Chem. Res. 1997, 30, 502-518. 
(14) That coordination bonds should be viewed as weak interactionsand therefore, part of the collection of binding interactions to be exploited in supramolecular synthetic chemistry-is itself interesting from a chemical cultural perspective. This notion represents a view that is distinctly that of an organic chemist (see, for example, ref 1). Generalizing, but perhaps not unfairly, organic chemists tend to view coordination chemistry largely as metal-based Lewis-acid/Lewis-base chemistry, with the resulting interactions falling in nearly the same category energetically and functionally as very strong hydrogen bonds. Inorganic chemists, on the other hand, tend to view coordination chemistry as legitimate coval ent bond chemistry; interactions between metals and main group elements are seen as the logical expansion of covalent chemistry beyond the confines of carbon, oxygen, nitrogen, hydrogen, phosphorous, and sulfur. Both, of course, are right, with many examples of coordination-type bonding clearly fitting one limiting view or the other. Here we've adopted terminology that intentionally offers up an ambiguous, or even inconsistent, view: Assemblies such as 2-9 are clearly supramolecular entities, especially from an organic chemist's point of view. At the same time, it's also useful to call these multimetallic assemblies "molecules"-an inorganic chemist's perspective-in particular to distinguish them from related semi-infinite coordination polymers.

(15) Recall that microporous, as used in the heterogeneous catalysis literature, signifies porosity on a nanometer, not micrometer, scale.

(16) Li, H. L.; Eddaoudi, M.; Laine, A.; O'Keeffe, M.; Yaghi, O. M. J Am. Chem. Soc. 1999, 121, 6096-6097.

(17) Dong, Y. B.; Smith, M. D.; zur Loye, H. C. Angew. Chem., Int. Ed. Engl. 2000, 39, 4271-4273.

(18) Dong, Y.-B.; Smith, M. D.; Layland, R. C.; Zur Loye, H.-C. Chem. Mater. 2000, 12, 1156-1161.

(19) Lawandy, M. A.; Huang, X. Y.; Wang, R. J .; Li, J .; Lu, J . Y.; Yuen, T.; Lin, C. L. Inorg. Chem. 1999, 38, 5410-5414.

(20) Biradha, K.; Hongo, Y.; Fujita, M. Angew. Chem., Int. Ed. Engl. 2000, 39, 3843-3845

(21) Carlucci, L.; Ciani, G.; Proserpio, D. M. Angew. Chem., Int. Ed. Engl. 1999, 38, 3488-3492.

(22) Withersby, M. A.; Blake, A. J .; Champness, N. R.; Cooke, P. A Hubberstey, P.; Li, W.-S.; Schroeder, M. Inorg. Chem. 1999, 38 $2259-2266$.

(23) Ibrahim, A. M. A. J . Organomet. Chem. 1998, 556, 1-9.

(24) That for medium to large sized compounds, van der Waals forces can become substantial and provide considerable stability.

(25) Stang, P. J .; Cao, D. H.; Saito, S.; Arif, A. M. J . Am. Chem. Soc. 1995, 117,6273-6283.

(26) If the molecular cavities were sufficiently large, of course, microporosity might well be obtained even if counterions resided in the cavities. For some applications, such a configuration might, in fact, be advantageous. For example, optically active counterions (for example, enantiomerically resolved tartrate ions) might be used to impart chirality to a channel. To the best of our knowledge, however, this idea has yet to be explored experimentally.

(27) We are unaware of any such compounds, but their design and assembly could easily be envisioned.

(28) Keefe, M. H.; Slone, R. V.; Hupp, J . T.; Czaplewski, K. F.; Snurr, R. Q.; Stern, C. L. Langmuir 2000, 16, 3964-3970.

(29) Slone, R. V.; Hupp, J . T.; Stern, C. L.; Albrecht-Schmitt, T. E. Inorg. Chem. 1996, 35, 4096-4097.

(30) Slone, R. V.; Hupp, J. T. Inorg. Chem. 1997, 36, 5422-5423.

(31) Sun, S.-S.; Lees, A. J . J . Am. Chem. Soc. 2000, 122, 8956-8967.

(32) Sun, S.-S.; Lees, A. J . Inorg. Chem. 1999, 38, 4181-4182.

(33) Sun, S.-S.; Silva, A. S.; Brinn, I. M.; Lees, A. J . Inorg. Chem. 2000, 39, 1344-1345.

(34) Morris, G. A.; Nguyen, S. T.; Hupp, J . T. unpublished results, 2001.

(35) Slone, R. V.; Benkstein, K. D.; Belanger, S.; Hupp, J . T.; Guzei, I. A.; Rheingold, A. L. Coord. Chem. Rev. 1998, 171, 221-243.

(36) Perhaps initially surprising is the finding that high-dilution, high-pressure, or related strategies are not required in order to avoid oligomer or polymer formation. Nor are catenated structures encountered-an interesting contrast to coordination polymers where grid interpenetration (the polymeric analogue of catenation) is routinely encountered. Mention should be made, however, of palladium and platinum-containing macrocycles devel oped by F ujita and co-workers that do display well-defined, controllable catenation behavior; Fujita, M.; I bukuro, F.; Hagihara, H.; Ogura, K. Nature 1994, 367, 720-723. Fujita, M. Fujita, N.; Ogura, K.; Yamaguchill, K. Nature 1999, 400, 5255.

(37) A recent report by Sun and Lees on a related hexametallic prismshaped compound suggests that $\mathbf{1 0}$ and $\mathbf{1 1}$ likely could be obtained also by coordinative self-assembly. Sun, S.-S.; Lees, A. J. Chem. Commun. 2001, 1, 103-104.

(38) Benkstein, K. D.; Hupp, J. T.; Stern, C. L. Angew. Chem., Int. Ed. Engl. 2000, 39, 2891-2893.
(39) Rajendran and Lu recently showed, however, that the desired rectangles could be obtained by in a stepwise process using trimethylamine $\mathrm{N}$-oxide to activate the $\mathrm{Re}(\mathrm{CO})_{5} \mathrm{Br}$ towards single point binding. The study also illustrated the delicate nature of the nonchelating rectangles: Despite careful handling, the photo luminescence reported for the pyrazine-bipyridine rectangle is actually that of the freeligands. Rajendran, T.; Manimaran, B Lee, F.-Y.; Lee, G.-H.; Peng, S.-M.; Wang, C. M.; Lu, K.-L. Inorg Chem. 2000, 39, 2016-2017.

(40) We also note that rectangular units of various sizes have been formed in coordination polymers. For example, see: Biradha, K.; Fujita, M. Chem. Commun. 2001, 15-16.

(41) Belanger, S.; Hupp, J . T.; Stern, C. L.; Slone, R. V.; Watson, D. F.; Carrell, T. G. J. Am. Chem. Soc. 1999, 121, 557-563.

(42) Cotton, F. A.; Lin, C.; Murillo, C. A. Inorg. Chem. 2001, 40, 478484.

(43) Cotton, F. A.; Lin, C.; Murillo, C. A. Inorg. Chem. 2001, 40, 472477.

(44) Cotton, F. A.; Daniels, L. M.; Lin, C.; Murillo, C. A. J . Am. Chem. Soc. 1999, 121, 4538-4539.

(45) Fox, O. D.; Wilkinson, E. J . S.; Beer, P. D.; Drew, M. G. B. Chem. Commun. 2000, 391-392.

(46) Fox, O. D.; Drew, M. G. B.; Beer, P. D. Angew. Chem., Int. Ed. Engl. 2000, 39, 136-140.

(47) Beer, P. D.; Cadman, J .; Lloris, J. M.; Martinez-Manez, R. Padilla, M. E.; Pardo, T.; Smith, D. K.; Soto, J . J . Chem. Soc., Dalton Trans. 1999, 127-134.

(48) Beer, P. D.; Cadman, J .; Lloris, J . M.; Martinez-Manez, R.; Soto, J .; Pardo, T.; Marcos, M. D. J . Chem. Soc., Dalton Trans. 2000, $1805-1812$.

(49) Kingston, J . E.; Ashford, L.; Beer, P. D.; Drew, M. G. B. J . Chem. Soc., Dalton Trans. 1999, 251-258.

(50) Alqaisi, S. M.; Galat, K.J .; Chai, M. H.; Ray, D. G.; Rinaldi, P. L.; Tessier, C. A.; Youngs, W. J . J . Am. Chem. Soc. 1998, 120, $12149-12150$

(51) Dinolfo, P. H. Unpublished results, 2000.

(52) Manimaran, B.; Rajendran, T.; Lu, Y.-L.; Lee, G.-H.; Peng, S.M.; Lu, K.-L. Eur. J . Inorg. Chem. 2001, 2001, 633-636.

(53) Cho, Y. L.; Uh, H.; Chang, S.-Y.; Chang, H.-Y.; Choi, M.-G.; Shin I.; J eong, K.-S. J . Am. Chem. Soc. 2001, 123, 1258-1259.

(54) Zhang, Y. S.; Wang, S. N.; Enright, G. D.; Breeze, S. R. J . Am. Chem. Soc. 1998, 120, 9398-9399.

(55) Cotton, F. A.; Caniels, L. M.; Lin, C.; Murillo, C. A. Chem. Commun. 1999, 841-842.

(56) Belanger, S.; Hupp, J . T. Angew. Chem., Int. Ed. Engl. 1999, 38, 2222-2224.

(57) Williams, M. E.; Zhang, J .; Morris, G. A.; Nguyen, S. T.; Hupp, J. T. J . Electronal. Chem., to be submitted.

(58) Williams, M. E.; Hupp, J. T. In The Encyclopedia of Electrochemistry; Bard, A. J ., Stratmann, M., Eds.; Wiley-VCH Publishers: 2000; Vol. 10

(59) Czaplewski, K. F.; Snurr, R. Q.; Hupp, J. T. Adv. Mater., submitted.

(60) Belanger, S.; Anderson, B. C.; Hupp, J. T. Proc. Electrochem. Soc. 1999, 98 (26), 208-214

(61) Benkstein, K. D. Ph.D. Thesis, Northwestern University, 2000

(62) Benkstein, K. D.; Williams, M. E. J. Phys. Chem. B, to be submitted.

(63) Whiteford, J . A.; Stang, P. J .; Huang, S. D. Inorg. Chem. 1998 37, 5595-5601.

(64) Whiteford, J . A.; Lu, C. V.; Stang, P. J . J . Am. Chem. Soc. 1997 119, 2524-2533.

(65) Mueller, C.; Whiteford, J . A.; Stang, P. J . J . Am. Chem. Soc 1998, 120, 9827-9837.

(66) Yu, S.-Y.; Kusukawa, T.; Biradha, K.; Fujita, M. J . Am. Chem. Soc. 2000, 122, 2665-2666.

(67) Yamanoi, Y.; Sakamoto, Y.; Kusukawa, T.; Fujita, M.; Sakamoto, S.; Yamaguchi, K. J . Am. Chem. Soc. 2001, 123, 980-981.

(68) Hiraoka, S.; Kubota, Y.; Fujita, M. Chem. Commun. 2000, 15091510.

(69) Hiraoka, S.; Fujita, M. J . Am. Chem. Soc. 1999, 121, 1023910240.

(70) Umemoto, K.; Yamaguchi, K.; Fujita, M.J . Am. Chem. Soc. 2000 122, 7150-7151.

(71) Aoyagi, M.; Biradha, K.; Fujita, M. J . Am. Chem. Soc. 1999, 121, $7457-7458$

(72) Maverick, A. W.; Buckingham, S. C.; Yao, Q.; Bradbury, J . R.; Stanley, G. G. J . Am. Chem. Soc. 1986, 108, 7430-7431.

(73) Benkstein, K. D.; Hupp, J. T.; Stern, C. L. J . Am. Chem. Soc 1998, 120, 12982-12983.

(74) Benkstein, K. D.; Hupp, J . T. Mol. Cryst. Liq. Cryst. Sci. Technol., Sect. A 2000, 342, 151-158.

(75) Sun, S.-S.; Lees, A. J . Chem. Commun. 2001, 103-104.

(76) Farrell, J . R.; Eisenberg, A. H.; Mirkin, C. A.; Guzei, I. A.; Liable Sands, L. M.; Incarvito, C. D.; Rheingold, A. L.; Stern, C. L. Organometallics 1999, 18, 4856-4868.

(77) Holliday, B. J .; Farrell, J. R.; Mirkin, C. A.; Lam, K.-C. Rheingold, A. L. J . Am. Chem. Soc. 1999, 121, 6316-6317. 
(78) Fujita, M.; Nagao, S.; Iida, M.; Ogata, K.; Ogura, K.J . Am. Chem Soc. 1993, 115, 1574-1576.

(79) Biradha, K.; Aoyagi, M.; Fujita, M.J . Am. Chem. Soc. 2000, 122, 2397-2398.

(80) Beer, P. D. Acc. Chem. Res. 1998, 31, 71-80.

(81) Beer, P. D.; Cadman, J. Coord. Chem. Rev. 2000, 205, 131-155.

(82) Beer, P. D.; Gale, P. A.; Chen, G. Z. J . Chem. Soc., Dalton Trans. 1999, 1897-1910

(83) Beer, P. D.; Berry, N.; Fox, O. D.; Padilla-Tosta, M. E.; Patell, S.; Drew, M. G. B. Chem. Commun. 2001, 199-200.

(84) Slone, R. V.; Yoon, D. I.; Calhoun, R. M.; Hupp, J. T. J . Am. Chem. Soc. 1995, 117, 11813-11814.

(85) Pikramenou, Z.; J ohnson, K. M.; Nocera, D. G. Tetrahedron Lett. 1993, 34, 3531-3534.

(86) Rudzinski, C. M.; Engebretson, D. S.; Hartmann, W. K.; Nocera D. G. J . Phys. Chem. A 1998, 102, 7442-7446.

(87) Rudzinski, C. M.; Hartmann, W. K.; Nocera, D. G. Coord. Chem Rev. 1998, 171, 115-123.

(88) Recall that for purely diffusion-controlled transport processes the time required for transport scales with the square of the distance to be traveled.

(89) Belanger, S.; Hupp, J . T.; Stern, C. L. Acta Crystallogr., Sect. C Cryst. Struct. Commun. 1998, C54, 1596-1600.

(90) McQuade, D. T.; Hegedus, A. H.; Swager, T. M. J . Am. Chem. Soc. 2000, 122, 12389-12390.

(91) Deans, R.; Kim, J .; Machacek, M. R.; Swager, T. M. J . Am. Chem Soc. 2000, 122, 8565-8566.

(92) McQuade, D. T.; Pullen, A. E.; Swager, T. M. Chem. Rev. 2000, $100,2537-2574$.

(93) Swager, T. M. Acc. Chem. Res. 1998, 31, 201-207.

(94) Bout, D. A. V.; Yip, W.-T.; Hu, D.; Fu, D.-K.; Swager, T. M.; Barbara, P. F. Science 1997, 277, 1074-1077.

(95) J arrett, M. R.; Finklea, H. O. Anal. Chem. 1999, 71, 353-357.

(96) Finklea, H. O.; Phillippi, M. A.; Lompert, E.; Grate, J . W. Anal Chem. 1998, 70, 1268-1276.

(97) Belanger, S.; Keefe, M. H.; Welch, J . L.; Hupp, J . T. Coord. Chem Rev. 1999, 190-192, 29-45.

(98) Chang, S. H.; Chung, K.-B.; Slone, R. V.; Hupp, J . T. Synth. Met. 2001, 117, 215-217.
(99) Mines, G. A.; Tzeng, B.; Stevenson; K. J ., Hupp, J. T. Angew Chem., Int. Ed. Engl., submitted 2001.

(100) Back, S.; Pritzkow, H.; Lang, H. Organometallics 1998, 17, 4144.

(101) Koehler, K.; Silverio, S. J .; Hyla-Kryspin, I.; Gleiter, R.; Zsolnai, L.; Driess, A.; Huttner, G.; Lang, H. Organometallics 1997, 16, 4970-4979.

(102) Ito, H.; Kusukawa, T.; Fujita, M. Chem. Lett. 2000, 598-599.

(103) Merlau, M. L.; Nguyen, S. T.; Hupp, J. T. Angew. Chem., Int. Ed. Engl., submitted 2001.

(104) Chorghade, M. S.; Hill, D. R.; Lee, E. C.; Pariza, R. J .; Dolphin, D. H.; Hino, F.; Zhang, L.-Y.'Pure Appl. Chem. 1996, 68, 753756.

(105) Collman, J. P.; Zhang, X.; Lee, V. J .; Uffelman, E. S.; Brauman, J. I. Science 1993, 261, 1404-1411.

(106) Rocha Gonsalves, A. M. d. A.; Pereira, M. M. J . Mol. Catal. A: Chem. 1996, 113, 209-221.

(107) J acobsen, E. N.; Zhang, W.; Muci, A. R.; Ecker, J . R.; Deng, L. . Am. Chem. Soc. 1991, 113, 7063-7064.

(108) J acobsen, E. N. In Comprehensive Organo-metallic Chemistry II; Abel, E. W., Stone, F. G. A., Wilkinson, E., Eds.; Pergamon: New York, 1995; Vol. 12, p 1097.

(109) J acobsen, E. N. In Catal. Asymmetric Synth.; Ojima, I., Ed. VCH: New York, 1993; pp 159-202.

(110) Koval, C. A.; Bryant, D. L.; Noble, R. D. Polym. Mater. Sci. Eng 1997, 77, 263-264.

(111) Goering, R. M.; Bowman, C. N.; Koval, C. A.; Noble, R. D.; Ashley, M. E. J . Membr. Sci. 2000, 172, 49-57.

(112) Goering, R. M.; Bowman, C. N.; Koval, C. A.; Noble, R. D.; Williamson, D. L. J . Membr. Sci. 1998, 144, 133-143.

(113) Longin, T. L.; Koval, C. A.; Noble, R. D. J . Phys. Chem. B 1998, 102, 2064-2075.

(114) Longin, T. L.; Koval, C. A.; Noble, R. D. J . Phys. Chem. B 1998, 102, 1036-1052.

(115) McDaniel, D. H.; Brown, H. C. J . Org. Chem. 1958, 23, 420.

CM 010176F 